\title{
Study of the mechanisms underlying the reversal of multidrug resistance of human neuroblastoma multidrug-resistant cell line SK-N-SH/MDR1 by low-intensity pulsed ultrasound
}

\author{
YANHUI SUN ${ }^{1}$, QIN LI $^{2}$, YOUHUA XU ${ }^{3}$, CONGLUN PU ${ }^{2}$, LIHUA ZHAO ${ }^{1}$, \\ ZHENHUA GUO $^{1}$, XIONGHUI DING ${ }^{1}$ and XIANQING JIN ${ }^{1,2}$ \\ ${ }^{1}$ Laboratory of Oncology; Departments of ${ }^{2}$ Surgery and ${ }^{3}$ Hematology, Children's Hospital of Chongqing \\ Medical University, Ministry of Education Key Laboratory of Child Development and Disorders, \\ Key Laboratory of Pediatrics in Chongqing and Chongqing International Science and Technology \\ Cooperation Center for Child Development and Disorders, Chongqing 400014, P.R. China
}

Received November 18, 2012; Accepted February 11, 2013

DOI: $10.3892 /$ or.2013.2337

\begin{abstract}
The aim of the present study was to investigate the underlying mechanism(s) involved in reversing multidrug resistance (MDR) of SK-N-SH/MDR1 by low-intensity pulsed ultrasound (LIPUS). Membrane alteration of SK-N-SH/ MDR1 cells exposed to LIPUS was analyzed by scanning electron microscopy (SEM). Immunofluorescence and western blotting were used $\backslash$ to detect changes in the expression of the MDR-related proteins P-glycoprotein (P-gp), multidrug resistance protein 1 (MRP1) and glutathione-S-transferase- $\pi$ (GST- $\pi$ ) after the optimum ultrasonic. The optimum ultrasonic conditions were $0.3 \mathrm{MHz}, 1.0 \mathrm{~W} / \mathrm{cm}^{2}, 40 \mathrm{sec}$ and the chemosensitivity of SK-N-SH/MDR1 cells was significantly increased $(\mathrm{P}<0.05)$. The optimum ultrasonic-induced perforation of the irradiated cell membranes was observed by SEM. The expression of P-gp was significantly decreased in the group treated by optimum ultrasonic $(\mathrm{P}<0.05)$, but not the expressions of MRP1 or GST- $\pi(P>0.05)$. We demonstrated that LIPUS effectively reverses the MDR of SK-N-SH/MDR1, presumably via augmenting membrane permeability and decreasing the P-gp expression of SK-N-SH/MDR1.
\end{abstract}

\section{Introduction}

Neuroblastoma is the most common extracranial solid tumor in infancy and childhood (1). Currently, chemotherapy remains the key therapy for neuroblastoma in the clinic. However, inevitable severe side-effects and multiple drug resistance (MDR)

Correspondence to: Professor Xianqing Jin, Department of Surgery, Children's Hospital of Chongqing Medical University, 136 Zhongshan 2nd Road, Yuzhong, Chongqing 400014, P.R. China

E-mail: etzhl@163.com

Key words: low-intensity pulsed ultrasound, multidrug resistance, P-glycoprotein, multidrug resistance protein 1, glutathione-Stransferase- $\pi$ limit its application. The mechanism of chemoresistance is complicated and current research involving reversal of MDR is still in the experimental stage (2-4). It is necessary to develop novel methods to enhance chemosensitivity and to reverse the MDR. Using high-intensity focused ultrasound (HIFU) treatment, the fringe area of tumor tissue treated by low intensity ultrasound is usually damaged, but is not necrotic (5-7). In addition, the tumor tissue is sensitive to chemotherapeutic drugs, even tissue that was insensitive to chemotherapy prior to HIFU therapy (8). The ability of LIPUS to reverse tumor MDR and enhance the sensitivity to chemotherapy drugs has, therefore, been confirmed (9-12).

The aim of the present study was to investigate the mechanism underlying low-intensity pulsed ultrasound (LIPUS) in reversing MDR of the human neuroblastoma multidrug resistant cell line SK-N-SH/MDR1. We applied various ultrasound intensities to determine the optimum ultrasonic to increase the sensitivity of SK-N-SH/MDR1 to chemotherapeutic drugs. We then analyzed the membrane alterations and MDR-related proteins [P-glycoprotein (P-gp), multidrug resistance protein 1 (MRP1), and glutathione-S-transferase- $\pi$ (GST- $\pi$ )] of SK-N-SH/MDR1 following optimum ultrasonic to elucidate the possible mechanism involved in reversing MDR.

\section{Materials and methods}

Cell culture. The HEK 293 cell line was a gift from professor Tong-Chuan He (Laboratory of Molecular Oncology, University of Chicago, USA). The human neuroblastoma cell line SK-N-SH was purchased from the American Type Culture Collection (ATCC, Manassas, VA, USA) and was preserved in our laboratory. The cells were maintained in Dulbecco's modified Eagle's medium/Nutrient Mixture F-12 (DMEM/F12) supplemented with $10 \%$ fetal bovine serum (PAA Laboratories $\mathrm{GmbH}$, Cölbe, Germany) at $37^{\circ} \mathrm{C}$ with $5 \% \mathrm{CO}_{2}$.

Preparation of high titer adenovirus vector supernatant. Recombinant adenoviral vectors expressing green fluorescence protein gene (GFP) and multidrug resistance gene 1 
(MDR1) (Ad-GFP-MDR1) and only GFP (Ad-GFP) were previously prepared in our laboratory (13). HEK 293 cells transducted with an appropriate multiplicity of infection (MOI) of Ad-GFP-MDR1 and Ad-GFP were harvested and frozen using a dry ice/methanol bath, immediately thawed in a $37^{\circ} \mathrm{C}$ water bath and vortexed. After expanding and purifying the cells using density gradient centrifugation (14), the high titer recombinant adenoviruses Ad-GFP-MDR1 and Ad-GFP were harvested.

Transduction of SK-N-SH cells with adenoviral vector supernatant. Logarithmic phase SK-N-SH cells were divided into 3 groups. Cells in group 1 transducted with Ad-GFP-MDR1, which served as the experimental group, were referred to as SK-N-SH/MDR1. Cells in group 2 transducted with Ad-GFP served as the control group and were referred to as SK-N-SH/GFP. A third group of untransducted cells served as a blank control, referred to as SK-N-SH.

The cells were plated on 96-well plates at a density of $2.0 \times 10^{5}$ cells/well. After culturing for $16 \mathrm{~h}$, the cells of each group were divided into 6 subgroups and transducted with adenoviral vector according to increasing MOI: $\mathrm{MOI}=5$, 10, 50, 100, 200 or 400. Each subgroup contained 6 repeated pores. The efficiency of transduction was quantified using fluorescence microscopy and flow cytometry was performed $48 \mathrm{~h}$ after transduction. The experiments were repeated in triplicate.

Ultrasound equipment and irradiation. A low-intensity ultrasonic irradiation system provided by Chongqing Medical University Ultrasonic Engineering Institute (transducer diameter, $1.8 \mathrm{~cm}$; frequency $0.3 \mathrm{MHz}$; China) was used. SK-N-SH/MDR1 cells were suspended in culture serum at $1 \times 10^{5}$ cells/well and prepared for irradiation. The SK-N-SH/MDR1 cell suspension was randomly divided into three groups: the $0.5 \mathrm{~W} / \mathrm{cm}^{2}$ group, the $1.0 \mathrm{~W} / \mathrm{cm}^{2}$ group and the $1.5 \mathrm{~W} / \mathrm{cm}^{2}$ group. The exposure times for the experimental group were 10, 20, 30, 40, 60, 90, 120, 160 and $200 \mathrm{sec}$ with sham irradiation for the control subgroup. Each subgroup contained $1 \mathrm{ml}$ cell suspension.

Analysis of the optimum irradiation of reversing MDR of $S K$-N-SH/MDR1 using methyl-thiazolyl-tetrazolium (MTT) assay. Following irradiation, $150 \mu \mathrm{l}$ of each subgroup of cell suspensions were plated on 96-well plates. The cell suspensions in the experimental and the control subgroup were divided into 3 repeated pores. Subsequently, the cells were stained with $20 \mu \mathrm{l}$ of $5.0 \mathrm{mg} / \mathrm{ml}$ sterile MTT solution [3-(4,5-dimethylthiazol2-yl)-2,5-diphenyltetrazolium bromide; Sigma, St. Louis, MO, USA] for $4 \mathrm{~h}$ at $37^{\circ} \mathrm{C}$, after which the medium was removed and thoroughly mixed with $100 \mu \mathrm{l}$ dimethyl sulfoxide (DMSO; Merck Inc., Whitehouse Station, NJ, USA) to dissolve formazan crystals. The cells were then agitated for $10 \mathrm{~min}$, and their absorbance was measured at $490 \mathrm{~nm}$ using a spectrophotometric microplate reader (Bio-Rad Laboratories In., Hercules, CA, USA). Each treatment group was analyzed in triplicate, and the experiment was repeated 3 times. The optimum ultrasonic irradiation conditions were selected by the value of $\mathrm{M}$ calculated using the following formula: $\mathrm{M}=$ average $\mathrm{OD}$ value of the experimental cells/average OD value of the control cells.
Analysis of chemosensitivity using MTT assay. To assess multidrug resistance of SK-N-SH, SK-N-SH /GFP, SK-N-SH/MDR1, and SK-N-SH/MDR1 with optimum irradiation, cells were plated on 96 -well plates at a density of $3.0 \times 10^{5}$ cells/well and incubated for $24 \mathrm{~h}$. Then, the medium was removed, replaced with fresh medium containing different concentrations of daunorubicin (DNR; Pharmacia Italia S.p.A, Milan, Italy), adriamycin (ADM; Pharmacia Italia S.p.A), vincristine (VCR; Wanle Pharmaceutical Factory, Shenzhen, China), and cyclophosphamide (CTX; Jiangsu Hengrui Pharmaceutical Co., Ltd., Jiangsu, China) and incubated for another $48 \mathrm{~h}$. The cells were then stained with $20 \mu 1$ of MTT solution $(5.0 \mathrm{mg} / \mathrm{ml})$ for $4 \mathrm{~h}$ at $37^{\circ} \mathrm{C}$, and the medium was removed and thoroughly mixed with $100 \mu \mathrm{l}$ dimethyl sulfoxide (DMSO) to dissolve formazan crystals. Absorbance was read at $490 \mathrm{~nm}$ using a spectrophotometric microplate reader (Bio-Rad Laboratories). The inhibition ratio of tumor cells at each drug concentration was calculated using the following formula: Inhibition ratio $(\%)=(1-$ average OD value of the experimental cells/average OD value of the control cells) $\mathrm{x} 100$. The half inhibiting concentration $\left(\mathrm{IC}_{50}\right)$ of each chemotherapeutic drug was determined from the inhibition ratio for each concentration (15).

Scanning electron microscopy (SEM). The structural changes of SK-N-SH/MDR1 cells exposed to optimum ultrasonic or sham irradiation were observed by SEM. The cells were washed with PBS twice and then suspended by PBS. The cell suspensions were dropped on a cover glass with a gold-plated membrane for $30 \mathrm{~min}$. The cells were fixed with $4 \%$ formalin for 2-3 min and then washed with triple PBS for $10 \mathrm{~min}$. The cells were then fixed with $1 \%$ osmic acid for 20-30 min and then washed with iced distilled water three times. The cells were soaked in the $2 \%$ tannin at $4^{\circ} \mathrm{C}$ overnight, dehydrated using graded ethanol, and lyophilized by tertiary butyl alcohol overnight. Finally, the cells were coated using a vacuum spray plating instrument and images were captured.

Immunofluorescence. Immunofluorescent staining was used to compare the localization and expression of P-gp, MRP1 and GST- $\pi$ in SK-N-SH /MDR1 exposed to optimum ultrasonic vs. sham irradiation. The cell slides were fixed with $2 \%$ paraformaldehyde and washed with PBS three times. The cell slides were blocked with rabbit serum for $10 \mathrm{~min}$ at room temperature and then incubated with rabbit polyclonal anti-P-gp antibody (diluted 1:200, Santa Cruz Biotechnology, Santa Cruz, CA, USA), rabbit polyclonal anti-MRP1 antibody (diluted 1:200, Santa Cruz Biotechnology) and rabbit polyclonal anti-GST- $\pi$ antibody (diluted 1:200, Santa Cruz Biotechnology), respectively, at $4^{\circ} \mathrm{C}$ overnight. Negative controls were conducted by exchange of primary antibody for PBS. After rinsing with PBS, the cell slides were incubated with anti-rabbit $\operatorname{IgG}$ conjugated with TRITC (diluted 1:100, Sigma) for $1 \mathrm{~h}$ at $37^{\circ} \mathrm{C}$ in darkness. The protein expression was observed by fluorescent microscopy after being counterstained with Hoechst and mounted with water-solubility mounting agents.

Western blotting. Western blot analysis was performed to investigate the expression of P-gp, MRP1 and GST- $\pi$. The cells were harvested and lysed in lysis buffer $(0.5 \%$ Nonidet 


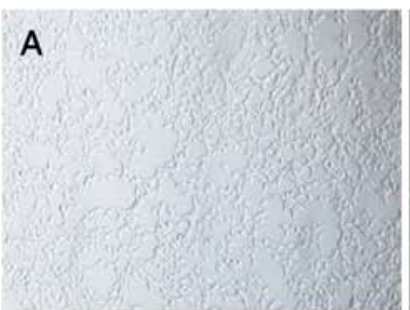

HEK $293(100 x)$

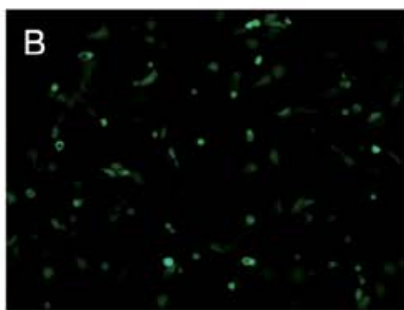

$24 \mathrm{~h}(100 \mathrm{x})$

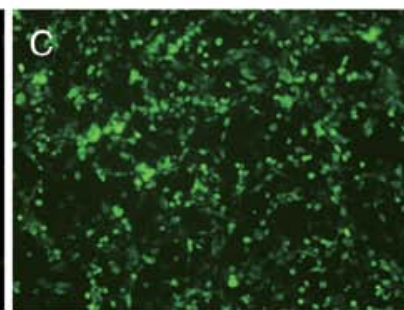

$48 \mathrm{~h}(100 \mathrm{x})$

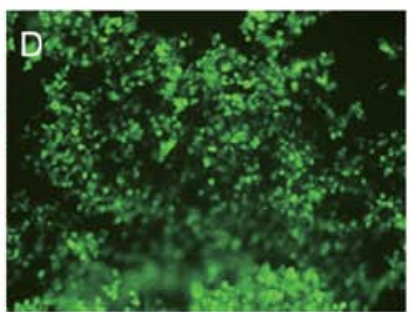

$96 \mathrm{~h}(100 \mathrm{x})$

Figure 1. GFP expression in HEK 293 cells transducted with the recombinant adenoviruses Ad-GFP-MDR1 and Ad-GFP (magnification, x100).
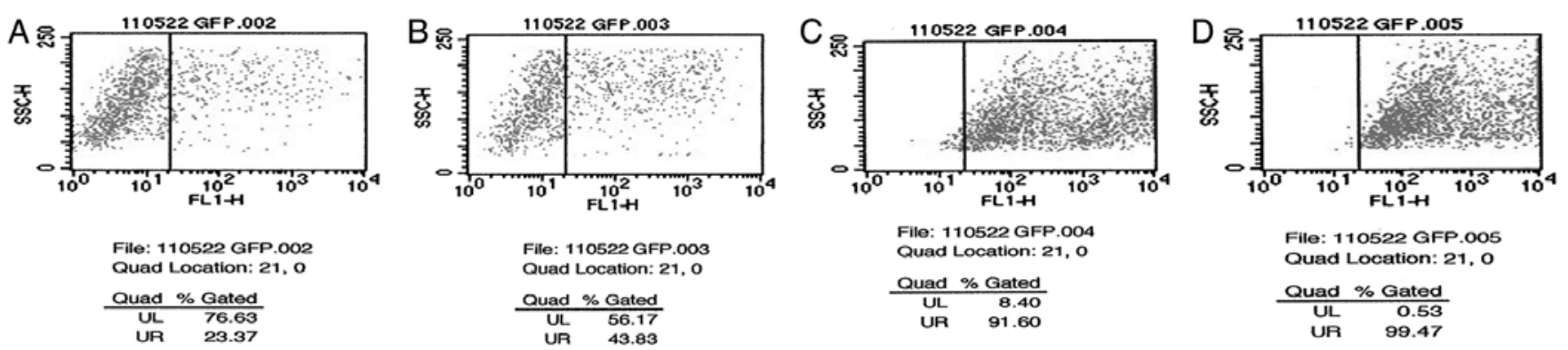

Figure 2. Transduction efficiency of SK-N-SH cells $48 \mathrm{~h}$ after transduction with Ad-GFP-MDR1 at different MOI. (A) MOI=10; (B) MOI=50; (C) MOI=100; (D) $\mathrm{MOI}=200$.

P-40, 10 mM Tris- $\mathrm{HCl} \mathrm{pH}$ 7.4, $150 \mathrm{mM} \mathrm{NaCl}, 1 \mathrm{mM}$ EDTA and $1 \mathrm{mM} \mathrm{Na} \mathrm{VO}_{4}$ ) supplemented with protease inhibitors and $1 \mathrm{mM}$ phenylmethylsulfonyl fluoride (PMSF). Equal amounts of proteins were separated by SDS-PAGE for western blot analysis, and the proteins were transferred to polyvinylidene fluoride (PVDF) membranes (Millipore Corp., Billerica, MA, USA), which were then blocked for $1 \mathrm{~h}$ with $5 \%$ non-fat milk in $10 \mathrm{mM}$ Tris- $\mathrm{HCl} \mathrm{pH} 7.5,100 \mathrm{mM} \mathrm{NaCl}$ and $0.1 \%$ (w/v) Tween-20. The membranes were first incubated with antibodies against $\beta$-actin, P-gp, MRP1 or GST- $\pi$ (all from Santa Cruz Biotechnology) overnight at $4^{\circ} \mathrm{C}$, followed by a $1.5-\mathrm{h}$ incubation with horseradish peroxidase-conjugated secondary antibody. The protein signals were detected using an enhanced chemiluminescence kit (Biyuntian Biotech, Beijing, China) and analyzed using the Bio-Rad (USA) imaging system and the associated software according to the manufacturer's instructions.

Statistical analysis. Results are presented as the means \pm standard deviation (SD). ANOVA and paired-samples t-test were performed to compare mean values between groups. The significance level was set at $5 \%$ for each analysis.

\section{Results}

Production of recombinant adenoviruses in HEK 293 cells. After culturing for 4-5 days, the HEK 293 cells transducted with the recombinant adenoviruses Ad-GFP-MDR1 and Ad-GFP transducted cells were observed floating in the media under a fluorescence microscope (Fig. 1). The viral titers of Ad-GFP-MDR1 and Ad-GFP ranged between 2.0 and $3.0 \times 10^{9}$ plaque forming units $(\mathrm{PFU}) / \mathrm{ml}$.
Fluorescence and adenovirus quantification in $S K-N-S H$ cells. The expression of GFP in SK-N-SH cells was observed $48 \mathrm{~h}$ after transduction using flow cytometry. As shown in Fig. 2, the transduction efficiency increased with increasing concentrations of adenovirus. Both the survival rate (over $80 \%)$ and the transduction efficiency ( $90 \%)$ of SK-N-SH cells were relatively high when the adenovirus $\mathrm{MOI}=100$. Thus, an MOI = 100 was used in further experiments. A multidrugresistant cell line SK-N-SH/MDR1 was transduced from an SK-N-SH cell line of neuroblastoma with adenoviral vectors encoding the MDR1 and the GFP (Ad-GFP-MDR1).

Optimum irradiation of reversing MDR of SK-N-SH/MDRI. LIPUS may damage the structural integrity of the membrane of tumor cells mechanically via sonoporation (16-19). In our experiment, the effect of proliferation could be excluded by reason of detecting $M$ value immediately after irradiation. As shown in Fig. 3, with the irradiation dose increased, sonoporation enhanced, more MTT entered tumor cells as a result of cell membrane permeability increasing, $M$ value increased. When the irradiation dose was beyond the peak, tumor cells were killed and $M$ value decreased. It could be concluded that the largest number of anticancer drugs enter the living cells for the strongest permeability of cell membrane at the peak $M$ value, and the peak M value of SK-N-SH /MDR1 for different doses of irradiation was the optimum ultrasonic. Thus, $0.3 \mathrm{MHz}$, $1.0 \mathrm{~W} / \mathrm{cm}^{2}$ and $40 \mathrm{sec}$ was chosen as the optimum ultrasonic condition, so that the experimental conditions would be consistent for the next experiment.

Sensitivity to anticancer drugs. The MTT assay allowed us to verify the drug sensitivity of SK-N-SH, SK-N-SH/MDR1, 
Table I. $\mathrm{IC}_{50}(\mu \mathrm{g} / \mathrm{ml})$ for DNR, ADM, VCR and CTX in SK-N-SH, SK-N-SH/GFP, SK-N-SH/MDR1 and SK-N-SH/MDR1+U.

\begin{tabular}{llccc}
\hline & \multicolumn{4}{c}{$\mathrm{IC}_{50}(\mu \mathrm{g} / \mathrm{ml})$} \\
\cline { 2 - 5 } Cell line & \multicolumn{1}{c}{$\mathrm{DNR}$} & $\mathrm{ADM}$ & $\mathrm{VCR}$ & CTX \\
\hline SK-N-SH & $0.066 \pm 0.011$ & $0.065 \pm 0.017$ & $0.366 \pm 0.043$ & $2.039 \pm 0.213$ \\
SK-N-SH/GFP & $0.070 \pm 0.020$ & $0.047 \pm 0.028$ & $0.314 \pm 0.102$ & $1.930 \pm 0.572$ \\
SK-N-SH/MDR1 & $0.629 \pm 0.092^{\mathrm{a}}$ & $0.484 \pm 0.118^{\mathrm{a}}$ & $1.526 \pm 0.184^{\mathrm{a}}$ & $8.022 \pm 1.044^{\mathrm{a}}$ \\
SK-N-SH/MDR1+U & $0.026 \pm 0.014^{\mathrm{b}}$ & $0.041 \pm 0.011^{\mathrm{b}}$ & $0.191 \pm 0.017^{\mathrm{b}}$ & $1.364 \pm 0.232^{\mathrm{b}}$ \\
\hline
\end{tabular}

Values are shown as the means $\pm \mathrm{SD}$. ${ }^{\mathrm{a}} \mathrm{P}<0.05$ analysis of $\mathrm{IC}_{50}$ of the same chemotherapy drugs in SK-N-SH/MDR1 compared with SK-N-SH. ${ }^{\mathrm{b}} \mathrm{P}<0.05$ analysis of $\mathrm{IC}_{50}$ of the same chemotherapy drugs in SK-N-SH/MDR1+U compared with SK-N-SH/MDR1.
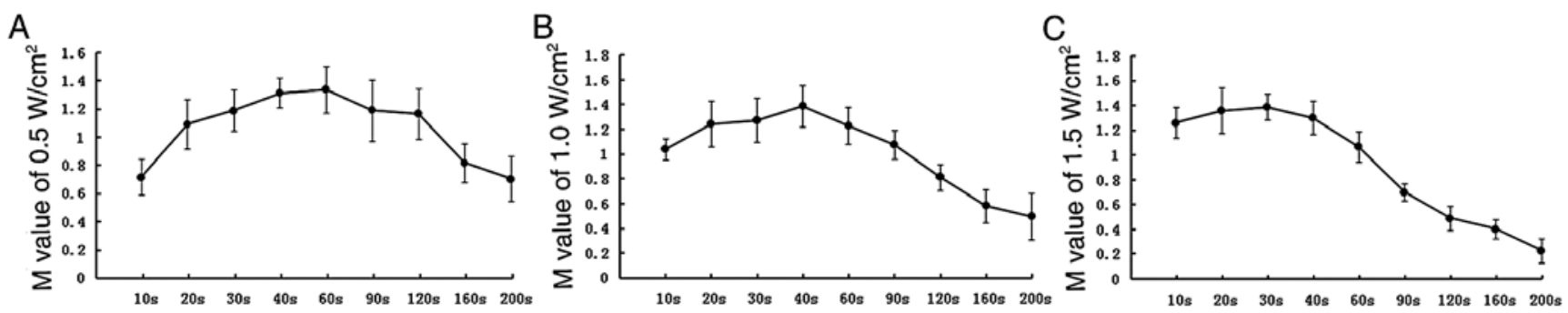

Figure 3. The $\mathrm{M}$ value of different intensity ultrasonic. (A) $0.5 \mathrm{~W} / \mathrm{cm}^{2}$ group; (B) $1.0 \mathrm{~W} / \mathrm{cm}^{2}$ group; (C) $1.5 \mathrm{~W} / \mathrm{cm}^{2}$ group.

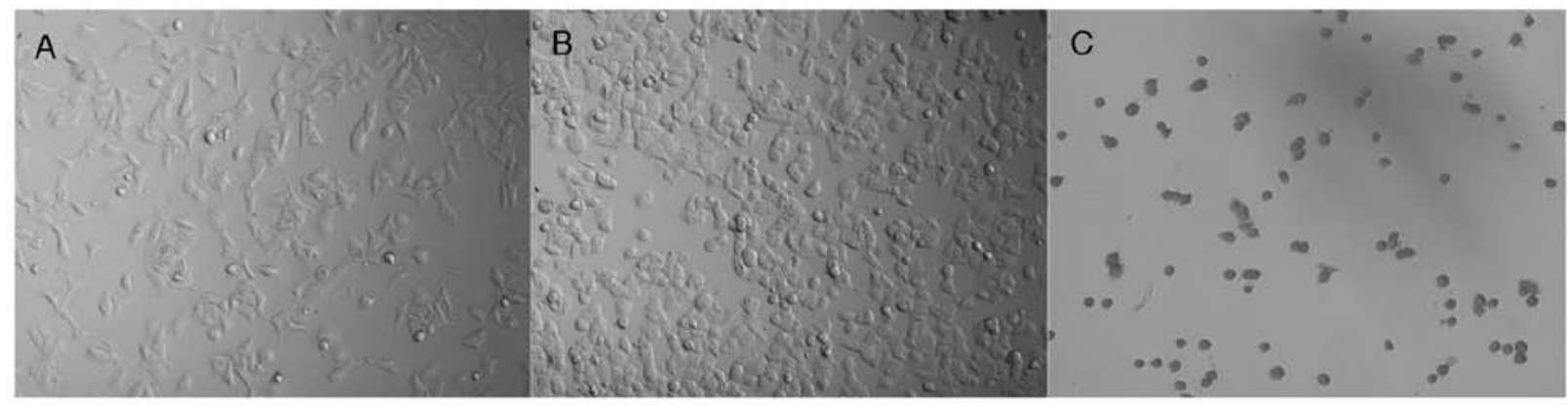

Figure 4. The morphology of SK-N-SH/MDR1 with different doses of irradiation (magnification, x200). (A) SK-N-SH/MDR1 with sham irradiation; (B) SK-N-SH/MDR1 with optimum irradiation; (C) SK-N-SH/MDR1 with $0.3 \mathrm{MHz}, 1.5 \mathrm{~W} / \mathrm{cm}^{2}, 200 \mathrm{sec}$ ultra-irradiation.

and SK-N-SH/MDR1 with optimum ultrasound (SK-N-SH/ MDR1+U) to anticancer drugs DNR, ADM, VCR, CTX and 5-FU, which are commonly used drugs in cancer therapy. As shown in Table I, the MDR1 transductants exhibited decreased sensitivity to the anticancer drugs $(\mathrm{P}<0.05)$ which confirmed the multidrug-resistant cell line SK-N-SH/MDR1 was constructed successfully. Notably, the $\mathrm{IC}_{50}$ of SK-N-SH/ MDR1 with the optimum irradiation was significantly lower than that of SK-N-SH and SK-N-SH/MDR1 cells, and the difference was statistically significant $(\mathrm{P}<0.05)$. This finding shows that the optimum irradiation could reverse the MDR of SK-N-SH /MDR1.

Effect of LIPUS on the morphology and microstructure of $S K-N-S H / M D R l$. To verify the effects of LIPUS on morphology and microstructure of SK-N-SH/MDR1, we observed the cells by microscopy following different doses of irradiation.
We found that with an increase in irradiation intensity, the SK-N-SH/MDR1 became swollen and round. The clearest difference occurred at the optimum irradiation (Fig. 4B). As the intensity of irradiation increased continuously, the cells were injured, they became necrotic and condensed (Fig. 4C).

To compare the changes prior to and following the optimum irradiation on a microstructural level, SEM was performed. In Fig. 5, SEM shows that SK-N-SH/MDR1, covered by microvilli on their cell surfaces, contained holes of various diameters in their cell membranes, and the number of microvilli was reduced (and even disappeared) following optimum irradiation.

Distribution and expression changes of $P-g p, M R P$ and $G S T-\pi$ in $S K-N-S H / M D R 1$ in optimum irradiation. Immunofluorescent staining revealed P-gp expression was significantly decreased in the membranes under the optimum irradiation, whereas 


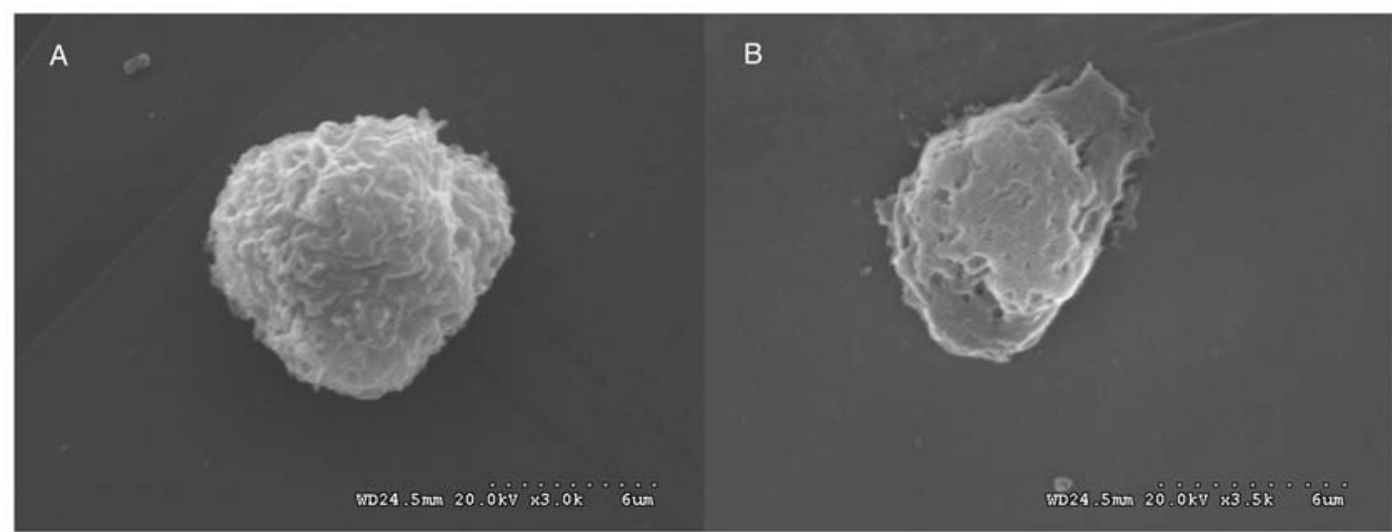

Figure 5. The microstructure of SK-N-SH/MDR1 by scanning electron microscopy prior to and following optimum irradiation. (A) SK-N-SH/MDR1 with sham irradiation; (B) SK-N-SH/MDR1 with optimum irradiation.
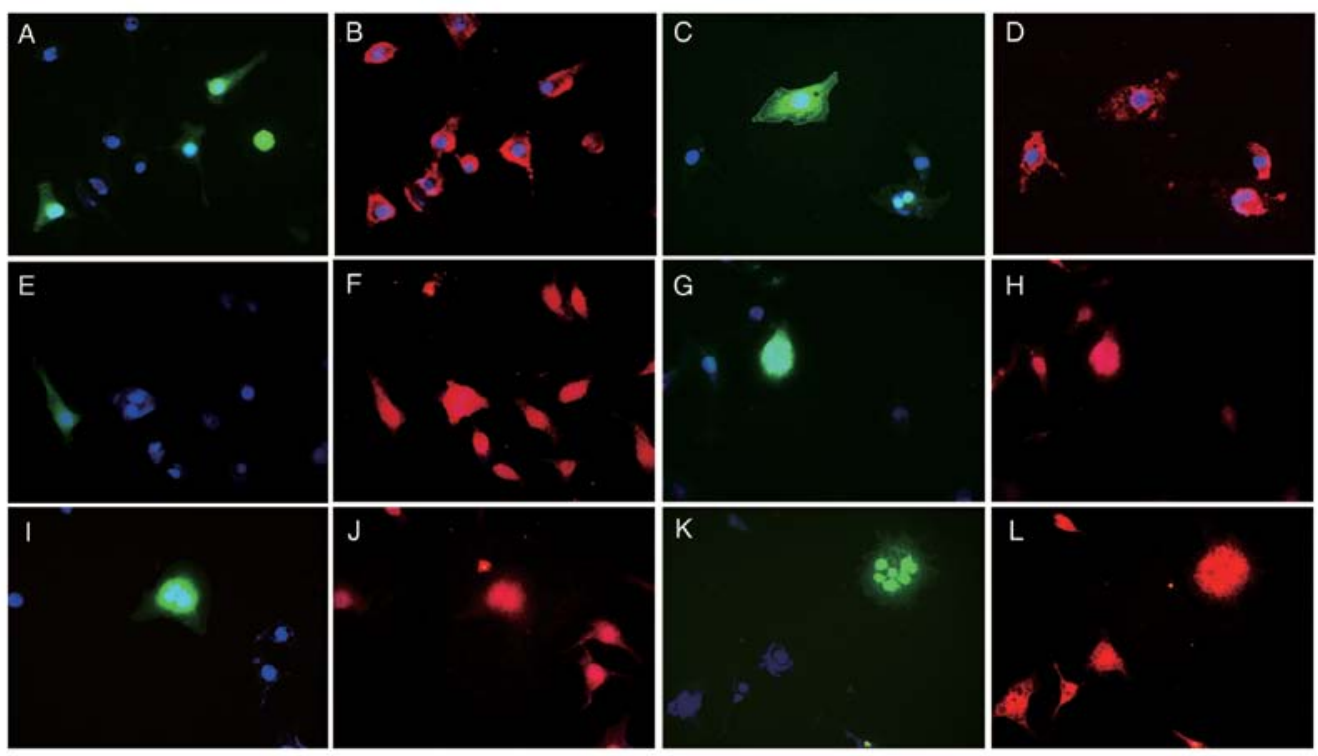

Figure 6. Distribution and expression changes of the P-gp, MRP1 and GST- $\pi$ in SK-N-SH/MDR1 in optimum irradiation as determined by immunofluorescent staining analysis (magnification, x400). (A-D) P-gp; (E-H) MRP1; (I-L) GST-л; (A, B, E, F, I and J) SK-N-SH/MDR1 with sham ultrasonic; (C, D, G, H, K and L) SK-N-SH/MDR1 with optimum ultrasonic; blue staining shows nucleus; green staining shows the GFP expression of Ad-GFP-MDR1; red staining shows multidrug resistance-related proteins.
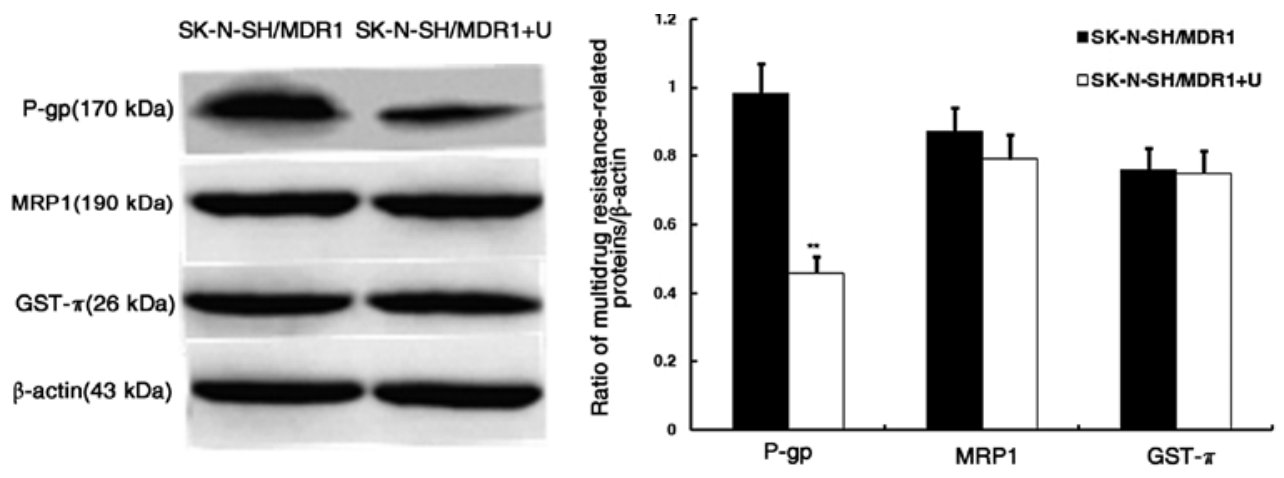

Figure 7. Expression changes of the P-gp, MRP and GST- $\pi$ in SK-N-SH/MDR1 in optimum irradiation as determined by western blot analysis. ${ }^{* *} \mathrm{P}<0.05$.

MRP and GST- $\pi$ in the cytoplasm and nucleus, respectively, did not change significantly, as indicated by fluorescent-red stain (Fig. 6). The expression of P-gp, MRP, and GST- $\pi$ in SK-N-SH by western blot analysis also revealed that P-gp was downregulated, but MRP and GST- $\pi$ were not differently expressed under the optimum irradiation (Fig. 7). 


\section{Discussion}

According to Jemal et al (20), malignant cancer is a leading cause of mortality (24.45\%). Chemotherapy is often ineffectual due to the MDR of some types of cancer. Tumor cell membrane barriers and the high expression of MDR-related proteins such as P-gp, MRP1 and GST- $\pi$ are the critical factors blocking anticancer drugs from playing their role (21-23). HIFU demonstrates advantages in tumor treatment (24-26). However, HIFU has significant side-effects such as long treatment times that result in dermal burns and lack of absorption by necrotic tumor tissue $(27,28)$. During the clinical application of HIFU, it was discovered that the fringe area of tumor tissue treated by LIPUS was more sensitive to anticancer drugs. In addition, even tissue that was insensitive to chemotherapy prior to HIFU therapy become sensitive, which confirmed that LIPUS could reverse the MDR of cancer cells.

In our study, resistant cell line SK-N-SH/MDR1 was constructed, and it was confirmed that $0.3 \mathrm{MHz}, 1.0 \mathrm{~W} / \mathrm{cm}^{2}$, a duration of $40 \mathrm{sec}$ was the optimum ultrasonic of reversing MDR of SK-N-SH/MDR1, through the experiments of sensitivity to anticancer drugs. The tumor cell membrane barrier is one of the critical factors that block anticancer drugs. Under the optimum ultrasonic, we observed by microscopy that the SK-N-SH/MDR1 cells were plump but not killed, and we also found, using SEM, that the cell membranes were perforated and their permeability was increased. Thus, LIPUS enhances the permeability of tumor cell membranes, allowing a larger amount of anticancer drugs into the cells. Currently, the majority of reversal agents inhibit the function of P-gp by competitive inhibition; however, the dose required for a visible effect is so toxic that it prohibits their use in the clinical setting (29,30). According to our immunofluorescence and western blot results, the P-gp was sparsely distributed in the cell membrane and significantly reduced under the optimum ultrasonic $\mathrm{P}<0.01$. However, MRP1 and GST- $\pi$ in the cytoplasm and nucleus, respectively, were not significantly differently expressed $\mathrm{P}<0.05$. We inferred that due to cell membrane damaged by sonoporation of LIPUS, P-gp was significantly reduced, and due to the structure and molecular environment of P-gp were destroyed, the discharge of anticancer drugs was reduced. The effect of optimum ultrasonic, however, was too low to damage the inner of cells and to kill cells, thus, MRP and GST- $\pi$ expressed in the cytoplasm and nucleus were not affected.

According to previous reports (31-34), LIPUS may also strengthen the transport of genes, proteins, and drugs to target organ tissues and cells, consequently improving their therapeutic effects. LIPUS may therefore become an important therapeutic modality in the future.

In conclusion, LIPUS can effectively reverse the MDR of SK-N-SH/MDR1. The underlying mechanism may involve damage to the cell structure and increased permeability of the cell membrane allowing more chemotherapeutic drugs to pass into the tumor cells. In addition, a reduction in the amount of P-gp due to LIPUS may prevent chemotherapeutic drugs from leaving the tumor cells. The potential of LIPUS in reversing MDR and improving the sensitivity to chemotherapeutic drugs provides a more targeted, safe, and stable method to treat tumors with fewer side-effects.

\section{Acknowledgements}

The authors thank Professor Tong-Chuan He (Laboratory of Molecular Oncology, University of Chicago, USA) for providing the HEK 293 cell line. The present study was supported by the National Natural Science Foundation of China (no. 39970768).

\section{References}

1. Liao XM and Leung KN: Indirubin-3'-oxime induces mitochondrial dysfunction and triggers growth inhibition and cell cycle arrest in human neuroblastoma cells. Oncol Rep 29: 371-379, 2013.

2. Shen H, Xu W, Chen Q, Wu Z, Tang H and Wang F: Tetrandrine prevents acquired drug resistance of K562 cells through inhibition of mdrl gene transcription. J Cancer Res Clin Oncol 136: 659-665, 2010.

3. Yuan Y, Shen H, Hu XY, Gu FY, Li MD and Zhong X: Multidisciplinary treatment with chemotherapy, targeted drug, and high-intensity focused ultrasound in advanced pancreatic carcinoma. Med Oncol 29: 957-961, 2012.

4. Ma B, Chai S, Li N, To KK, Kan WL, Yang D and Lin G: Reversal of P-glycoprotein-mediated multidrug resistance by a synthetic $\alpha$-aminoxy peptidomimetic. Int J Pharm 424: 33-39, 2012.

5. Marin A, Sun H, Husseini GA, Pitt WG, Christensen DA and Rapoport NY: Drug delivery in pluronic micelles: effect of high-frequency ultrasound on drug release from micelles and intracellular uptake. J Control Release 84: 39-47, 2002.

6. Feng Y, Tian ZM, Wan MX and Zheng ZB: Low intensity ultrasound-induced apoptosis in human gastric carcinoma cells. World J Gastroenterol 14: 4873-4879, 2008.

7. Man J, Shelton RM, Cooper PR and Scheven BA: Low-intensity low-frequency ultrasound promotes proliferation and differentiation of odontoblast-like cells. J Endod 38: 608-613, 2012.

8. Rapoport N: Combined cancer therapy by micellar-encapsulated drug and ultrasound. Int J Pharm 277: 155-162, 2004.

9. Liu Y, Cho CW, Yan X, Henthorn TK, Lillehei KO, Cobb WN and Ng KY: Ultrasound-induced hyperthermia increases cellular uptake and cytotoxicity of P-glycoprotein substrates in multidrug resistant cells. Pharm Res 18: 1255-1261, 2001.

10. Cho CW, Liu Y, Cobb WN, Henthorn TK, Lillehei K, Christians U and $\mathrm{Ng} \mathrm{KY:} \mathrm{Ultrasound-induced} \mathrm{mild} \mathrm{hyperthermia} \mathrm{as} \mathrm{a} \mathrm{novel}$ approach to increase drug uptake in brain microvessel endothelial cells. Pharm Res 19: 1123-1129, 2002.

11. Yu T, Hu K, Bai J and Wang Z: Reversal of adriamycin resistance in ovarian carcinoma cell line by combination of verapamil and low-level ultrasound. Ultrason Sonochem 10: 37-40, 2003.

12. Yu T, Huang X, Hu K, Bai J and Wang Z: Mechanisms of reversal of adriamycin resistance in human ovarian carcinoma cell line by ultrasound. Int J Gynecol Cancer 14: 76-81, 2004.

13. Zhao L, Jin X, Xu Y, Guo Y, Liang R, Guo Z, Chen T, Sun Y and Ding $X$ : Functional study of the novel multidrug resistance gene HA117 and its comparison to multidrug resistance gene 1. J Exp Clin Cancer Res 29: 98-105, 2010.

14. Luo J, Deng ZL, Luo X, Tang N, Song WX, Chen J, Sharff KA, Luu HH, Haydon RC, Kinzler KW, Vogelstein B and He TC: A protocol for rapid generation of recombinant adenoviruses using the AdEasy system. Nat Protoc 2: 1236-1247, 2007.

15. Zhao L, Sun Y, Li X, Jin X, Xu Y, Guo Z, Liang R, Ding X, Chen $\mathrm{T}$ and Wang S: Multidrug resistance strength of the novel multidrug resistance gene HA117: compared with MRP1. Med Oncol 28: 1188-1195, 2011.

16. Xia CY, Liu YH, Wang P and Xue YX: Low-frequency ultrasound irradiation increases blood-tumor barrier permeability by transcellular pathway in a rat glioma model. J Mol Neurosci 48: 281-290, 2012

17. O'Reilly MA, Waspe AC, Ganguly M and Hynynen K: Focused-ultrasound disruption of the blood-brain barrier using closely-timed short pulses: influence of sonication parameters and injection rate. Ultrasound Med Biol 37: 587-594, 2011.

18. McDannold N, Vykhodtseva $\mathrm{N}$ and Hynynen K: Effects of acoustic parameters and ultrasound contrast agent dose on focused-ultrasound induced blood-brain barrier disruption. Ultrasound Med Biol 34: 930-937, 2008.

19. Hayashi S, Yamamoto M, Tachibana K, Ueno Y, Bu G and Fukushima T: Mechanism of photofrin-enhanced ultrasoundinduced human glioma cell death. Anticancer Res 29: 897-905, 2009. 
20. Jemal A, Siegel R, Xu J and Ward E: Cancer statistics, 2010. CA Cancer J Clin 60: 277-300, 2010.

21. Lazaris AC, Kavantzas NG, Zorzos HS, Tsavaris NV and Davaris PS: Markers of drug resistance in relapsing colon cancer. J Cancer Res Clin Oncol 128: 114-118, 2002.

22. Berger W, Setinek U, Hollaus P, Zidek T, Steiner E, Elbling L, Cantonati H, Attems J, Gsur A and Micksche M: Multidrug resistance markers P-glycoprotein, multidrug resistance protein 1, and lung resistance protein in non-small cell lung cancer: prognostic implications. J Cancer Res Clin Oncol 131: 355-363, 2005.

23. Sui H, Fan ZZ and Li Q: Signal transduction pathways and transcriptional mechanisms of ABCB1/Pgp-mediated multiple drug resistance in human cancer cells. J Int Med Res 40: 426-435, 2012.

24. Satava RM: Advanced technologies and the future of medicine and surgery. Yonsei Med J 49: 873-878, 2008.

25. Orsi F, Arnone P, Chen W and Zhang L: High intensity focused ultrasound ablation: a new therapeutic option for solid tumors. J Can Res Ther 6: 414-420, 2010.

26. Zini C, Hipp E, Thomas S, Napoli A, Catalano C and Oto A: Ultrasound- and MR-guided focused ultrasound surgery for prostate cancer. World J Radiol 4: 247-252, 2012.

27. Xu G, Luo G, He L, Li J, Shan H, Zhang R, Li Y, Gao X, Lin S and Wang G: Follow-up of high-intensity focused ultrasound treatment for patients with hepatocellular carcinoma. Ultrasound Med Biol 37: 1993-1999, 2011.

28. Mougenot C, Köhler MO, Enholm J, Quesson B and Moonen C: Quantification of near-field heating during volumetric MR-HIFU ablation. Med Phys 38: 272-282, 2011.
29. Hung HY, Ohkoshi E, Goto M, Bastow KF, Nakagawa-Goto K and Lee KH: Antitumor agents. 293. Nontoxic dimethyl-4,4'-dimethoxy-5,6,5',6'-dimethylenedioxybiphenyl-2,2'-dicarboxylate (DDB) analogues chemosensitize multidrug-resistant cancer cells to clinical anticancer drugs. J Med Chem 55: 5413-5424, 2012.

30. Tang X, Gu X, Ren Z, Ma Y, Lai Y, Peng H, Peng S and Zhang Y: Synthesis and evaluation of substituted dibenzo[c,e]azepine-5ones as P-glycoprotein-mediated multidrug resistance reversal agents. Bioorg Med Chem Lett 22: 2675-2680, 2012.

31. Scheven BA, Millard JL, Cooper PR, Lea SC, Walmsley AD and Smith AJ: Short-term in vitro effects of low frequency ultrasound on odontoblast-like cells. Ultrasound Med Biol 33: 1475-1482, 2007.

32. Hassan MA, Buldakov MA, Ogawa R, Zhao QL, Furusawa Y, Kudo N, Kondo T and Riesz P: Modulation control over ultrasound-mediated gene delivery: evaluating the importance of standing waves. J Control Release 141: 70-76, 2010.

33. Zhang $\mathrm{H}$, Jiang $\mathrm{H}$, Wang $\mathrm{H}$, Zhao J, Chen B and Wang $\mathrm{X}$ : Ultrasound mediated drug-loaded nanoparticles crossing cell membranes as a new strategy to reverse cancer multidrug resistance. J Nanosci Nanotechnol 11: 1834-1840, 2011.

34. Huang Q, Deng J, Xie Z, Wang F, Chen S, Lei B, Liao P, Huang N, Wang Z, Wang Z and Cheng Y: Effective gene transfer into central nervous system following ultrasound-microbubblesinduced opening of the blood-brain barrier. Ultrasound Med Biol 38: 1234-1243, 2012. 